\title{
Perfil gráfico das imagens publicadas na revista Chanaan
}

\author{
Graphic profile of images published in the magazine Chanaan
}

\author{
MOREIRA, Luiza Avelar; Design; Universidade Federal do Espírito Santo \\ luiza.avelarmoreira@gmail.com
}

FONSECA, Letícia Pedruzzi; Doutora; Universidade Federal do Espírito Santo

leticia.fonseca@ufes.br

\section{Resumo}

O presente artigo apresenta os resultados da análise gráfica das imagens publicadas na revista Chanaan, veiculada de 1936 a 1939, na cidade de Vitória, capital do estado do Espírito Santo. Para tanto, foi desenvolvida uma ficha de coleta de dados digital para sistematizar a observação da construção gráfica das imagens, considerando tipologias, características de construção visual e ainda o uso concomitante de elementos ornamentais, tipográficos e caligráficos. Os dados coletados foram automaticamente tabulados para que fosse possível gerar dados estatísticos e infográficos para uma apresentação de resultados mais clara e eficiente. As imagens foram desmembradas nas categorias fotografia, composição de página, ilustração e fotomontagens, sendo a categoria fotografia a mais recorrente no acervo. Constatou-se que o impresso valorizava o conteúdo imagético, com nível elevado de experimentações nas composições de imagens e páginas, buscando retratar a vida social e política da elite capixaba e o desenvolvimento próspero da cidade.

Palavras Chave: perfil gráfico; imagens; revista.

\section{Abstract}

This article presents the results of a graphic analysis of the images published in Chanaan, $a$ magazine that circulated from 1936 to 1939, in the city of Vitória, capital of the state of Espirito Santo, Brazil. For this purpose, a data collection form was developed aiming to systematize the observation of the graphic construction of the images, considering their typologies, visual construction, and the simultaneous use of ornamental, typographic and calligraphic elements. The collected data was automatically fed into a table that enabled the extraction of statistics and the creation of infographics for a clearer and more efficient presentation of the results. The images were separated into photography, page composition, illustration and photomontage categories, of which photography was the most recurrent kind in the collection. It was then apparent that the publication valued image content most, with a high level of experimentation in the composition of images and pages, seeking to portray the social and political life of the Capixaba elite and the prosperous development of the city.

Keywords: graphic profile; images; magazine. 


\section{Introdução}

A presente pesquisa buscou alcançar resultados inéditos sobre a memória gráfica capixaba por meio de análise imagética da revista Chanaan, veiculada de 1936 a 1939, na cidade de Vitória, capital do estado do Espírito Santo.

Em relação ao contexto em que a Chanaan estava inserida, pode-se dizer que o ano de 1930 foi marcado por dois fatos decisivos para a economia e política nacional: a quebra da bolsa de valores de Nova York, que refletiu na produção de café, açúcar, algodão e borracha, e a crise política ligada à ruptura da política café com leite. Com a revolução de 30 e o início do governo provisório, Getúlio Vargas passou a governar diante de forte tensão política. Dentre suas ações, está a criação do Conselho Nacional do Café, o qual tomou medidas protecionistas para recuperar a atividade cafeeira, basilar para a economia do estado do Espírito Santo na época (MARTINUZZO, 2008).

Durante esse período, o Espírito Santo teve como figura marcante o militar João Punaro Bley que atuou como interventor do Estado após a eleição de Vargas. Bley teve uma grande ajuda do jornal "Diário da Manhã", no qual os seus feitos foram exaltados. Além disso, teve sua imagem política atrelada ao crescimento de Vitória, uma vez que promoveu obras de infraestrutura, segurança, saúde liquidação das dívidas do Estado, estímulo nas exportações e no movimento imigratório para as regiões Sul e Norte do Estado. O período em que governou foi marcado pelo surgimento de revistas de vanguarda. A postura que antes era exclusivamente literária foi substituída por matérias mais independentes com colaboradores diversos. Na mesma época, notou-se também a aparição de caricaturas e a forte influência do modernismo nos impressos (MARTINUZZO, 2008).

Acredita-se que a criação da revista Chanaan deve-se ao apoio de um grupo social, provavelmente cafeeiro, para promover Bley e seu governo, e concorrer com a então principal revista local, intitulada Vida Capichaba, que circulou de 1923 a 1959 (AZERÊDO; FONSECA, 2017). Bley e sua esposa apareciam frequentemente nas imagens da revista, sozinhos ou dentre outras personalidades em eventos sociais e políticos. Logo na primeira edição pode-se observar o recado de boas-vindas do próprio interventor, acompanhado de uma pequena legenda, sua fotografia de página inteira e sua assinatura, endossando a sua satisfação e aprovação com o lançamento da revista para o público capixaba. A imagem aparece em grande destaque logo nas primeiras páginas e foi uma das poucas a ser impressa em cores.

O conteúdo da revista Chanaan era direcionado para a elite, nela encontravam-se matérias sobre festas, celebridades, pontos turísticos e exaltava o desenvolvimento econômico e cultural do estado do Espírito Santo. Foram publicadas diversas matérias em outras línguas e correspondentes internacionais produziram conteúdos exclusivos para a revista, que circulou também em Salvador, Belo Horizonte, Rio de Janeiro, São Paulo e até fora do país. Pode-se dizer que a revista tinha uma identidade visual forte e ao longo dos seus quatro anos de publicação foram encontrados variados recursos visuais e diversas experimentações (AZERÊDO et al, 2015).

\section{Metodologia}

O Laboratório de Design: História e Tipografia ( LadHT) construiu ao longo de anos um protocolo metodológico para padronizar e dar suporte às diferentes pesquisas sobre revistas, jornais e outros impressos, realizadas por sua equipe de pesquisadores. A primeira frente metodológica diz respeito à aproximação do pesquisador com o contexto sócio-histórico do impresso, incluindo revisão bibliográfica e a realização de coletas de dados adicionais, como 
entrevistas, por exemplo. A segunda frente da pesquisa é focada na análise gráfica do impresso, dividida em 7 etapas: identificação e mapeamento de acervos, registro fotográfico do acervo, organização do acervo digital, elaboração da ficha de análise do impresso, coleta de dados do impresso, análise dos dados e discussão dos resultados (FONSECA et al, 2016).

Para a coleta de dados, foi criada a Ficha Individual de Imagens (FII), com variáveis específicas para a avaliação das imagens do acervo, que identificou tipologias e características de construção visual e ainda o uso da imagem junto a elementos ornamentais, tipográficos e caligráficos. As categorias coletadas foram: Ano, Edição, Tipologia, Forma, Tamanho Aproximado, Cor, Orientação, Consistência, Gama, Enquadramento, Naturalismo, Moldura, Fios, Assinatura, Legenda e Planos Fotográficos (AZERÊDO et al, 2015; AZERÊDO; FONSECA, 2016; ASHWIN, 1982 apud LIMA, 2009; BERTIN, 1983 apud LIMA, 2009; PASTE, 2011; RODRIGUEZ, [2010-? ]). Com o objetivo de ter uma análise mais eficiente foram consideradas quatro classificações principais para imagens: ilustração, fotografia, fotomontagem e composição de página, já que cada grupo apresentava características particulares a serem avaliadas necessitando assim de variáveis específicas (MOREIRA; FONSECA, 2017).

A Fll se mostrou uma ferramenta ágil e prática ao ser usada para tabular dados de acervos extensos como o da revista Chanaan, nela foram preenchidas 1.331 fichas em um mês. Os dados coletados na ficha construída digitalmente foram automaticamente tabulados, o que permitiu a organização, o cruzamento de informações e a geração de resultados estatisticamente válidos (MOREIRA; FONSECA, 2017).

A planilha gerada a partir dos dados imputados apresentou cada questão em formato de coluna, que foi posteriormente editada para uma visualização mais clara dos dados. Na primeira coluna encontrava-se o nome da edição de acordo com a nomenclatura do acervo, seguido de ano, edição e tipo de imagem, assim pode-se filtrar facilmente os elementos para obtenção de dados específicos de acordo com a demanda da pesquisa.

O uso de tabelas dinâmicas e recursos de formatação condicional durante a análise dos dados foi de grande valor, já que promoveu uma interpretação dos dados com maior rapidez e com maior eficiência, facilitando o cruzamento de resultados de diferentes variáveis e excluindo possibilidades de erro, uma vez que produziram saídas estatísticas automáticas.

\section{Resultados}

Após a tabulação dos dados, contabilizou-se o número de 2.412 imagens publicadas durante os quatro anos de circulação da Chanaan. Essas imagens apareciam sozinhas, em uma composição de página ou compondo uma fotomontagem. Foram analisadas 27 tipologias diferentes, considerando que uma imagem poderia estar inserida em mais de uma classificação para que se abrangesse melhor todas as suas possibilidades. A tipologia "mulheres" apresentou 158 imagens, sendo a maior em porcentagem, com $11,7 \%$ do total; seguida da tipologia "paisagens" com 124 imagens, sendo 9,2\% do total; e a tipologia "eventos sociais" com 118 imagens, sendo $8,8 \%$ da totalidade. O exemplar com o maior número de imagens publicadas foi a edição dupla 22 e 23, do ano de 1938, com 177 imagens. Já a edição com menor número foi a 33, do ano de 1939, com apenas 42 imagens. As edições do ano de 1936 foram as que mais publicaram imagens, somando 404, seguidas das de 1937 com 368 imagens, depois em 1938 com 
226 imagens e, por fim, em 1939 com 134 imagens. Os dados deixam claro que o número de imagens foi reduzido a cada ano de publicação da revista, podendo ser um indício da diminuição dos investimentos feitos na revista. O tipo de imagem mais recorrente foi o de composição de página com 461 identificadas, muito próximo da classificação fotografia, que contabilizou 410 imagens.

Imagem 1: Infográfico sobre resultados Gerais da revista Chanaan

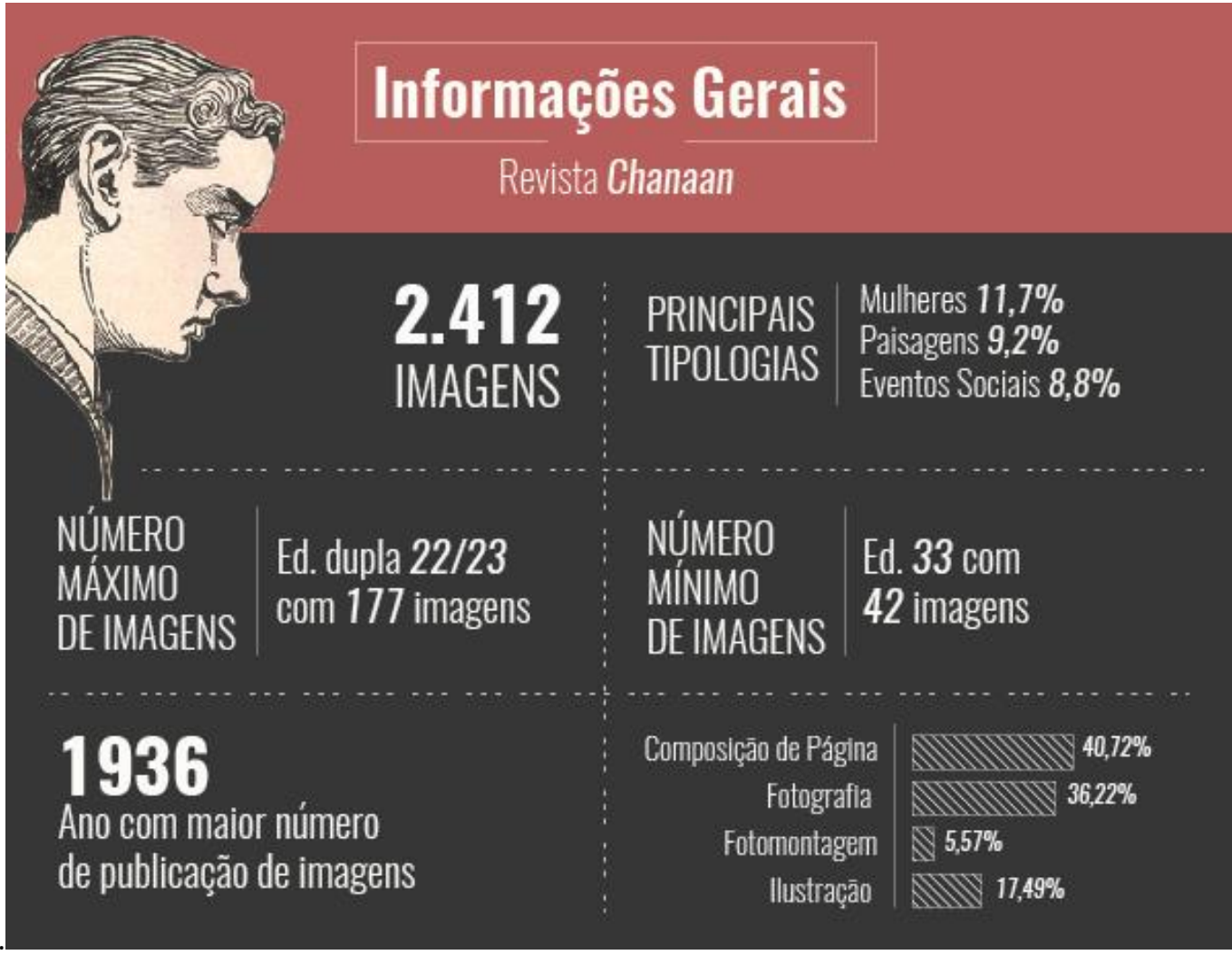

Fonte: Imagem produzida pelo autor.

A edição dupla $22 \backslash 23$ teve o maior número em publicação de imagens, contendo grande número de fotomontagens e composições de página. Pode-se perceber uma grande riqueza em experimentações com imagens recortadas em diversos formatos e tamanhos trazendo uma diagramação mais dinâmica e de caráter experimental. A edição traz inúmeras fotos de locais da grande Vitória e personalidades da elite local.

Conhecendo o acervo da revista foi possível relacionar os acontecimentos históricos, políticos e sociais com as matérias que foram publicadas no periódico. Foram encontrados, com frequência, nas primeiras páginas da revista, alguns comentários de personalidades políticas, dentre eles se encontrava a seguinte frase de Punaro Bley: "Chanaan é o espirito santo na sua expressão geographica, historica, economica e cultural" (Chanaan, ed. 10. capa 02). Citação seguida de frases que ressaltavam que a revista era responsável por veicular e atestar o desenvolvimento intelectual e cultural do Estado. Em outros momentos, a mesma publicou notas que atestavam o sucesso de seu lançamento em outras capitais, afirmando que seu conteúdo foi "um indice de cultura digno de grandes centros de actividade intellectual" (Chanaan, ed. 13. p. 
55). Além disso, tais notas apresentaram elogios sobre a revista, os quais haviam sido publicados em outras periódicos nacionais, como: Correio da Manhã, Revista da Semana e Tanagra do Rio de Janeiro, e Correio do Paraná de Curitiba.

A principal tipologia, "mulheres", enaltecia a beleza e elegância de distintas damas da sociedade Capixaba, demonstrando o ideal de civilidade de uma capital com vida social desenvolvida. Quando apresentadas nas legendas eram chamadas por senhorinha e seu nome de solteira, mas quando se tratavam de senhoras casadas, normalmente, além de serem chamadas por seu nome, também era apresentado o nome do esposo, acompanhado de sua posição social ou o cargo em que ele se apresentava. Em destaque, ocupando página inteira na primeira edição da revista e utilizando cores na impressão, foi publicada a foto da senhora Alzira Douvat Bley, acompanhada de uma mensagem de agradecimento à revista e lhe desejando uma "existência fecunda e fulgurante" (Chanaan, ed. 01. p. 43). Como uma fotografia poderia se encaixar em mais de uma tipologia, muitas imagens de mulheres também eram ligadas a tipologias como: "moda", apresentando croquis e exemplos de estilo; "eventos sociais", como por exemplo, em casamentos que eram frequentemente publicados na revista; na tipologia "artes", no caso de atrizes e cantoras nacionais e internacionais; "crianças", pois muitas mulheres eram apresentadas à sociedade junto a seus filhos; e a tipologia "ilustrações lúdicas", como em "aberturas de capítulos" nas quais se encontravam ilustrações e vinhetas que acompanhavam uma matéria. Já as imagens classificadas na tipologia "paisagens" exaltavam belezas do Estado e a prosperidade da capital Vitória, comunicando aos seus leitores as belezas e riquezas de um Estado que estava em grande desenvolvimento sócio-econômico na era de governo Bley e Vargas. Às vezes as imagens eram acompanhadas de legendas, quase que poéticas, trazendo certo tom lúdico, idealizando acontecimentos cotidianos, como um pôr do sol, a chegada da noite ou alguma paisagem da Capital. Também foram frequentemente apresentadas paisagens de outros estados e seus pontos turísticos.

Na tipologia "eventos sociais" foram registrados os eventos com a alta sociedade de Vitória, que era retratada como uma Capital de vida social ativa e relevante. Pode-se destacar como eventos recorrentes na revista os bailes de carnaval, eventos no Clube Saldanha da Gama e no Clube Vitória e registros de casamentos. As imagens publicadas sobre os bailes de carnaval apresentavam misturas com diferentes tratamentos gráficos, como por exemplo, fotos com molduras e fios, muitas vezes acompanhadas de pequenas ilustrações com temáticas carnavalescas e letterings. Os eventos mais recorrentes e retratados nos clubes da Capital eram bailes temáticos, almoços e jantares. E sobre os casamentos divulgados na revista, observou-se que as imagens variavam entre o retrato da noiva ou do casal, na igreja ou em ambientes usados como cenários. Por fim, notou-se que na tipologia "eventos sociais", as inaugurações de estabelecimentos públicos ou privados também tinham espaço nas páginas da revista, o que poderia ser considerada mais uma maneira de divulgar e apresentar a prosperidade e desenvolvimento socioeconômico do Estado.

\section{Fotografia}

Na categoria "fotografia", foi observada uma consistência homogênea, ou seja, 96,24\% das fotografias analisadas não apresentaram misturas com outros recursos gráficos como letterings, tipografia e ilustrações. O formato de $89,22 \%$ das fotografias analisadas era retangular e $1,47 \%$ quadrado, sobrando apenas $9,32 \%$ para formatos mais experimentais como irregulares, ovais e redondos. As fotografias foram encontradas em tamanhos variados, sendo uma coluna mais 
recorrente com 30,24\%, seguido em ordem decrescente de página inteira com $26,10 \%$, meia página com $20,24 \%$, duas colunas com $16,34 \%$, topo da página com $3,41 \%$, três colunas com $2,68 \%$ e rodapé com $0,98 \%$. A maioria das fotografias foi publicada em preto e branco, somando $97,06 \%$ do total, e nas raras vezes em que foram publicadas em cores, foi utilizada somente uma cor adicional, juntamente com o preto e branco, ou uma cor única. A orientação vertical somou $62,08 \%$ e a horizontal $35,99 \%$, apenas $1,93 \%$ foi publicada usando a orientação transversal. Os fios foram pouco utilizados nas fotografias, sendo que apenas $1,46 \%$ das imagens continha algum tipo de fio composto ou simples. $81,71 \%$ apresentaram legendas e $16,14 \%$ das fotografias continham assinatura, desta forma pôde-se listar nomes de fotógrafos e estúdios fotográficos que atuavam na imprensa capixaba e nacional.Foram utilizados todos os tipos de planos fotográficos sendo o Plano Geral o mais significativo usado em $60,34 \%$ das fotografias, seguido de Médio Corto com 15,09\%, Plano Detalhe com 6,33\%, Primer Plano com 6,33\%, Médio com 5,60\%, Americano com 6,33\% e Primeiríssimo Primer Plano com 0,24\%.

Os nomes identificados nas assinaturas e legendas foram: Los Rios, Estúdio Photographico Paes, Fábio Tancredi, Mazzei, N. Madeira da Silva, Antonio Sobral, Osvaldo Câmara, T. Dias, Erbe, Edmond, Lucarelli, Álvaro Conde, Domingos Gialfredo, Trajano da Cruz e Octavio Paes.

Nas próprias matérias e fotografias publicadas pela revista, foi possível ter acesso a informações sobre os fotógrafos citados acima. Em um texto intitulado de "Nossa Capa" , informações sobre a composição da capa daquela edição foram passadas a fim de engrandecer a inclusão do trabalho fotográfico de Oswaldo Camara como uma participação especial para a equipe de "artistas gráficos" responsáveis pela composição daquele clichê (Chanaan, ed. 04 p. 13).

Outros dois textos, com o título de "Nossos Photographos", anunciaram uma exposição que iria ocorrer com as fotografias "elegantes" e de "técnica perfeita" do fotógrafo Mazzei, além de citar algumas personalidades da sociedade capixaba que Mazzei fotografou e seriam protagonistas em suas exposição (Chanaan, ed. 04 p. 13). Mazzei é citado como elemento de inestimável valor para a revista Chanaan, fato que se confirma quando observado o número elevado de imagens que o fotógrafo publicou durante os anos de publicação da revista. Em outro momento, uma reportagem inteira é dedicada ao fotógrafo, conhecido por expor seus retratos de "expoentes do set capixaba" e da "belleza paysagistica" do Estado com grande finesse e cuidado, além de citar algumas tipologias frequentemente registradas por Mazzei como: paisagens, arquitetura, personalidades, mulheres, eventos sociais e estabelecimentos comerciais e públicos (Chanaan, ed. 02 p. 20). Em uma foto publicada de Carmelia Mazzei, a legenda se refere a Mazzei como "esplendido photographo tão apreciado pela sociedade capichaba e que tem promovido a tão bella propaganda do Espírito Santo, atravez de sua profissão" (Chanaan, ed. 17 p. 16).

O fotógrafo Paes também foi citado com uma pequena lista de personalidades políticas e paisagens que ele fotografou, e depois também foi aclamado como figura notável da imprensa "ilustrada" capixaba (Chanaan, ed. 04 p. 13) . O artista ficou conhecido por seus clichês que tornaram as "belezas de sua terra" conhecidas em outros locais. Em outro momento, também foi publicada a foto de Paes com uma pequena nota informando que o mesmo mantinha um estúdio na capital Vitória, além de possuir uma exposição permanente de suas obras em seu estabelecimento (Chanaan, ed. 16 p. 40).

Dando continuidade a apresentação dos fotógrafos que colaboraram com a revista, Antonio Sobral foi citado como responsável por divulgar as belezas da cidade de Cachoeiro de 
Itapemirim através de suas "belas telas" publicadas nas páginas da revista (Chanaan, ed. 04 p. 13)

Já o fotógrafo T. Dias teve sua foto divulgada e em sua legenda era citado como um "artista que a Bahia possue", reforçando o fato de que a Chanaan possuia correspondentes em outros Estados (Chanaan, ed. 05 e 06 p. 02).

Ademais, a fotografia de Domingos Gialfredo foi publicada com legenda que o identificava como ganhador do prêmio da Kodak Brasileira (Chanaan, ed. 32 p. 18).

Imagem 2: Fotografias da revista Chanaan.
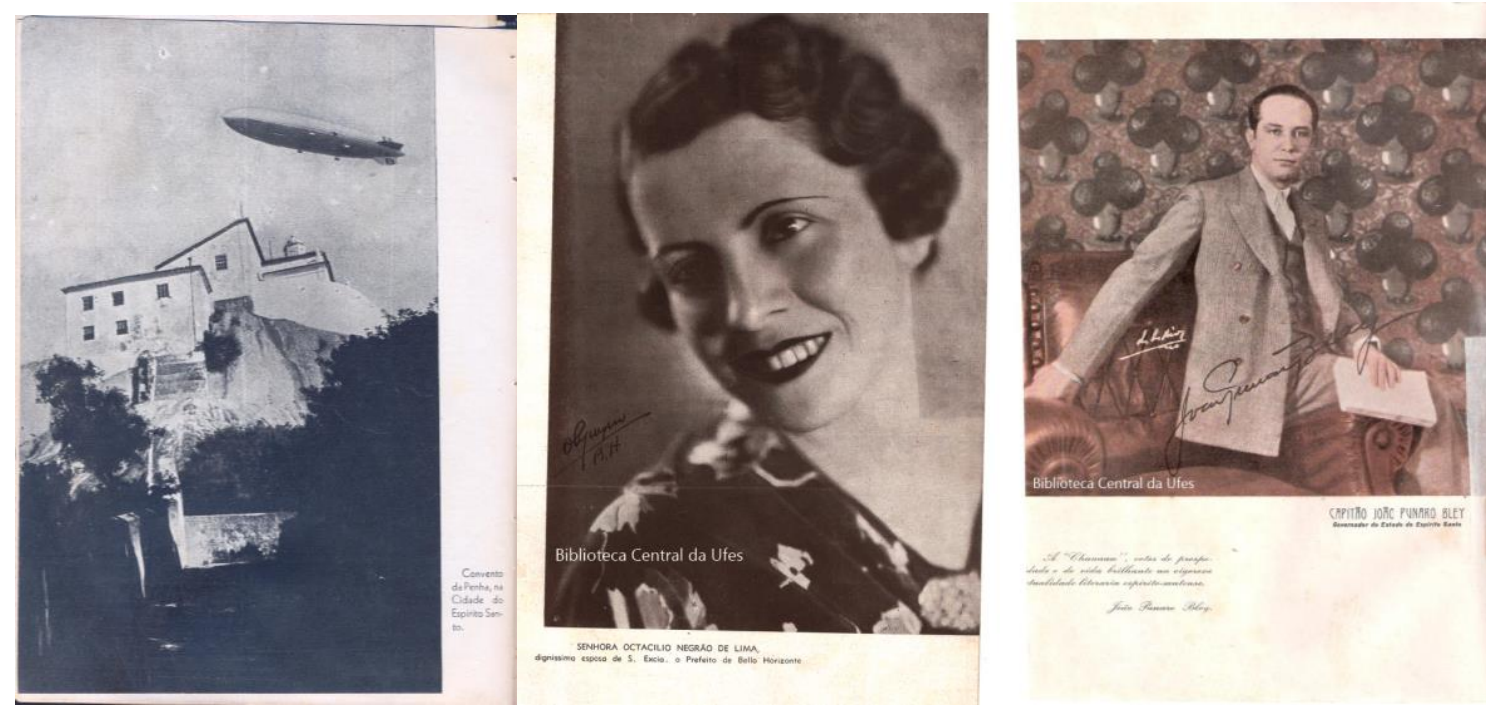

Fonte: Revista Chanaan Ed. 21, página 48, ano 1937; Revista Chanaan Ed. 07, página 55, ano 1936; Revista Chanaan Ed. 01, página 22, ano 1936. 
Imagem 3: Infográfico com os resultados da análise da categoria Fotografia na revista Chanaan.

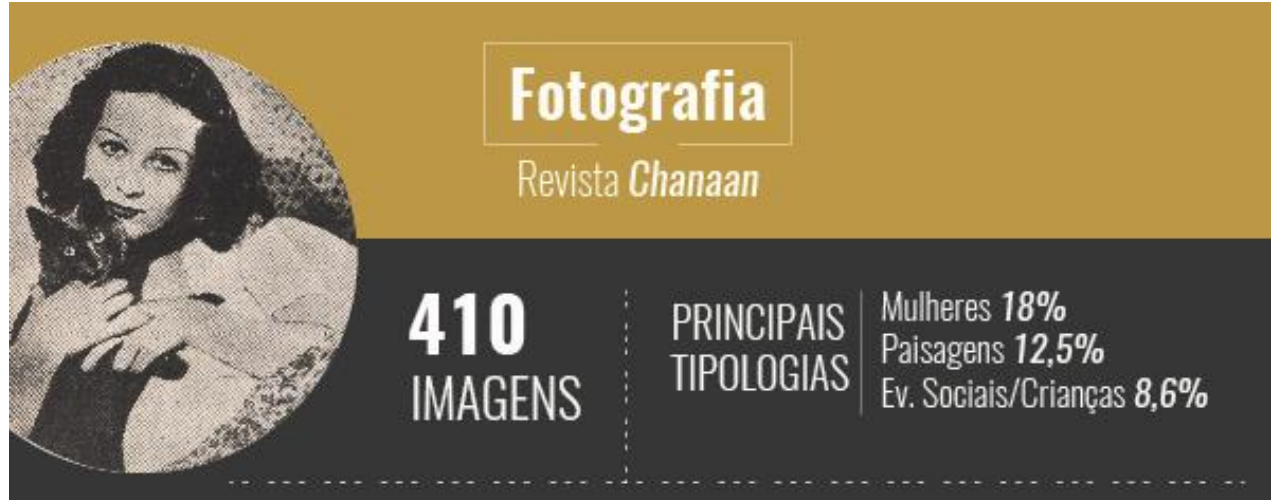

PERFIL GRÁFICO
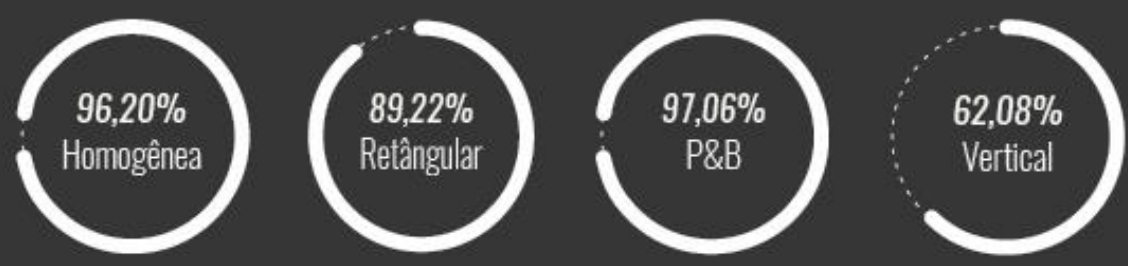

APRESENTAVAM

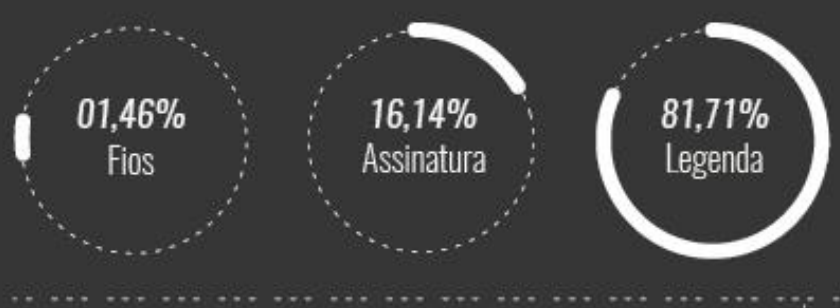

\section{MOLDURA}

Ausente $95,85 \%$

Composta $01,71 \%$

Simples $02,44 \%$

\section{PLANOS}

FOTOGRÁFICOS

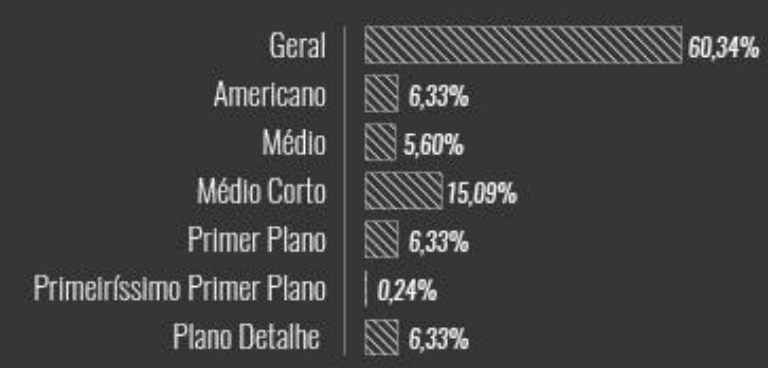

$30,24 \%$

Ocupava Uma Coluna

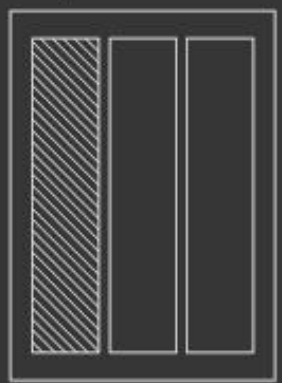

Fonte: Imagem produzida pelo autor.

\section{Fotomontagem}

As composições de fotomontagem eram $67,70 \%$ compostas por fotografia e $20,40 \%$ por 
lettering, apontando então que apesar de ser uma categoria diferente, a fotografia foi predominante em sua totalidade. Além disso, as fotomontagens de formato irregular somavam $59,55 \%$ do total, reforçando o caráter experimental que era empregado nesta categoria. Ademais, em 69,84\% das ocorrências ocuparam a página inteira, podendo indicar interesse em evidenciar esse caráter mais inovador. Foram utilizadas nas fotomontagens somente o preto e branco em $98,39 \%$ de suas composições. A orientação ficou equilibrada entre vertical com 42,06\% e horizontal com 48,60\% e apenas 9,35\% transversal. Apenas 30,16\% das fotomontagens apresentaram margens e $98,54 \%$ não apresentaram nenhum tipo de fio. $11,10 \%$ apresentaram assinatura e 68,25\% apresentaram legenda.

As fotomontagens apresentaram caráter mais experimental, já que o recorte dos elementos eram agrupados para que se formasse uma nova imagem, diferentemente da composição de página, que usava a sobreposição ou encaixe para ter uma diagramação diferenciada. Assim pode-se observar que a maioria das fotomontagens apresentou algum elemento de forma irregular, recortado propositalmente a fim de formar uma nova composição.

Imagem 4: Fotomontagens da revista Chanaan.
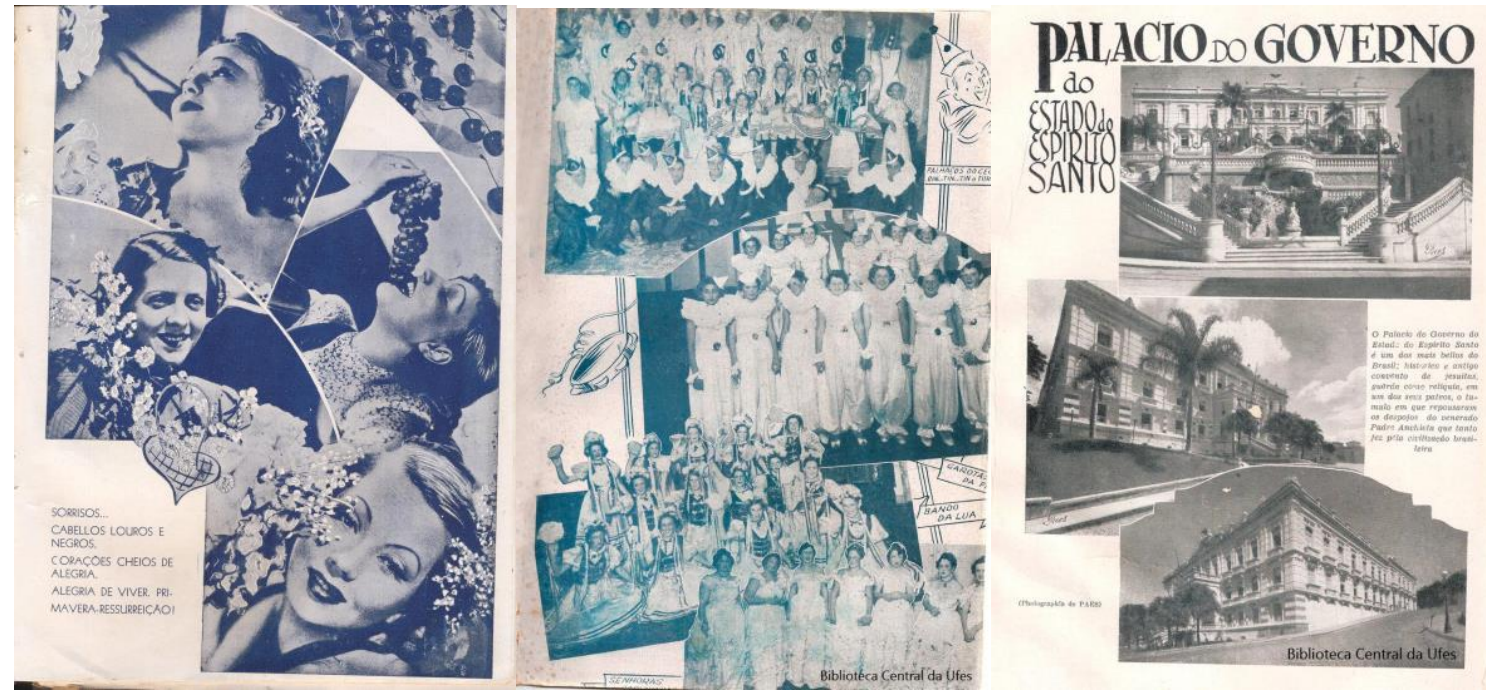

Fonte: Revista Chanaan Ed. 27, página 20, ano 1937; Revista Chanaan Ed. 03, página 33, ano 1936; Revista Chanaan Ed. 02, página 31, ano 1936. 
Imagem 5: Infográfico com os resultados da análise da categoria Fotomontagem na revista Chanaan.

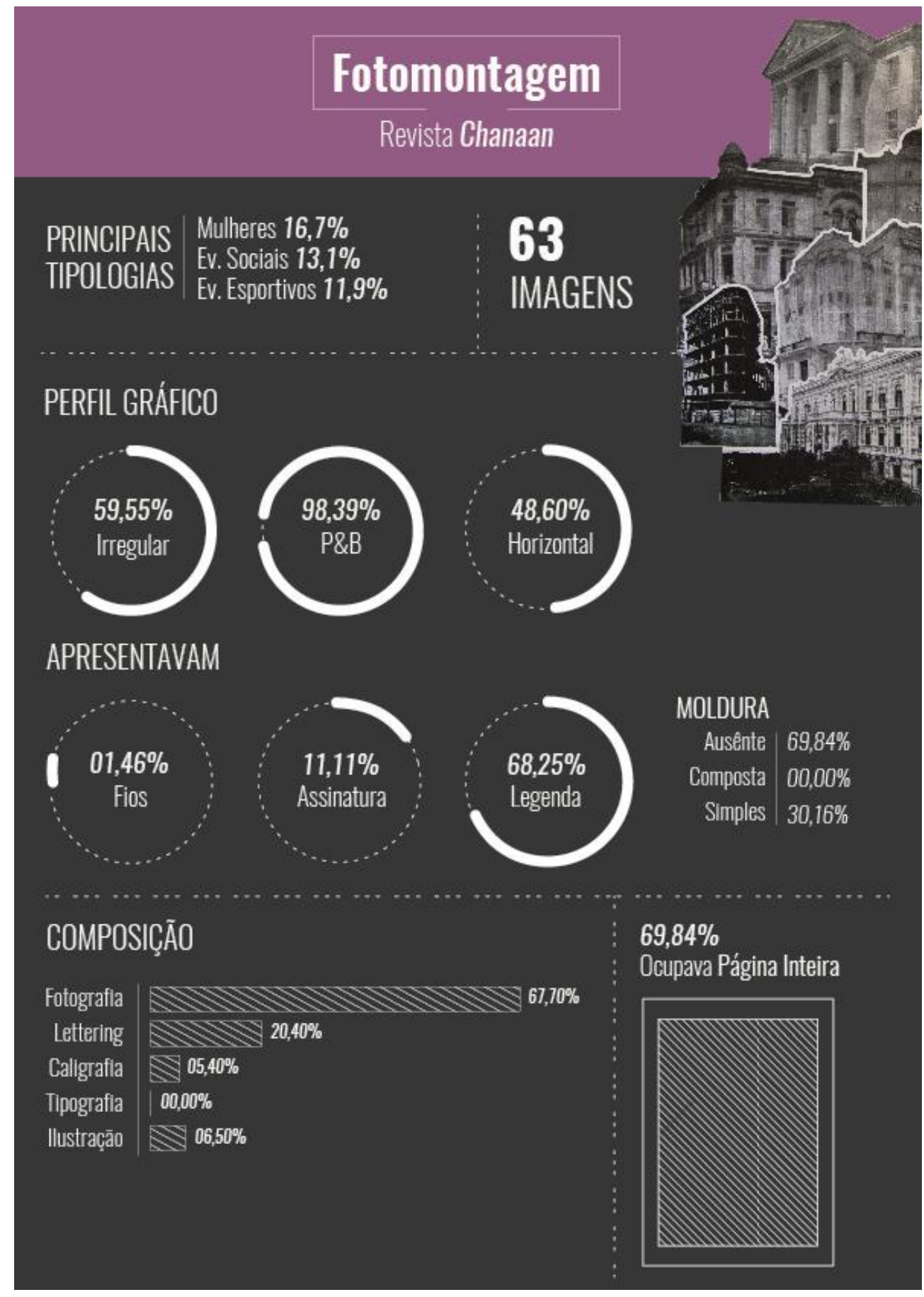

Fonte: Imagem produzida pelo autor.

\section{Composição de página}

As composições de página eram formadas em $77,27 \%$ por fotografias, evidenciando mais 
uma vez que a fotografia foi o tipo de imagem mais recorrente na composição dos elementos imagéticos. 66,82\% das composições eram dispostas de forma retangular, sendo seguido de $27,17 \%$ de maneira irregular, abrindo espaço para diagramações mais audaciosas. A maioria, com 79,39\%, ocupava a página inteira, e meia página com $15,84 \%$. 98,47\% das composições de página apareciam somente em preto e branco e grande parte das orientações se dividiram em horizontal com $52,24 \%$, vertical com $39,41 \%$ e constando apenas $8,35 \%$ para transversais. $85,87 \%$ não apresentaram nenhum tipo de margens e $86,74 \%$ nenhum tipo de fio. $82,83 \%$ apresentaram legendas e não foi encontrada nenhuma assinatura.

Observa-se que nas composições de imagens os elementos eram dispostos para criar uma diagramação diferenciada que buscava se adaptar ao texto e normalmente continham a mesma temática. As imagens aparecem juntas nas páginas, mas mantém sua unidade, diferentemente da fotomontagem, em que os elementos se tornam mesclados, sem muita delimitação entre si.

Imagem 6: Composições de página na revista Chanaan.

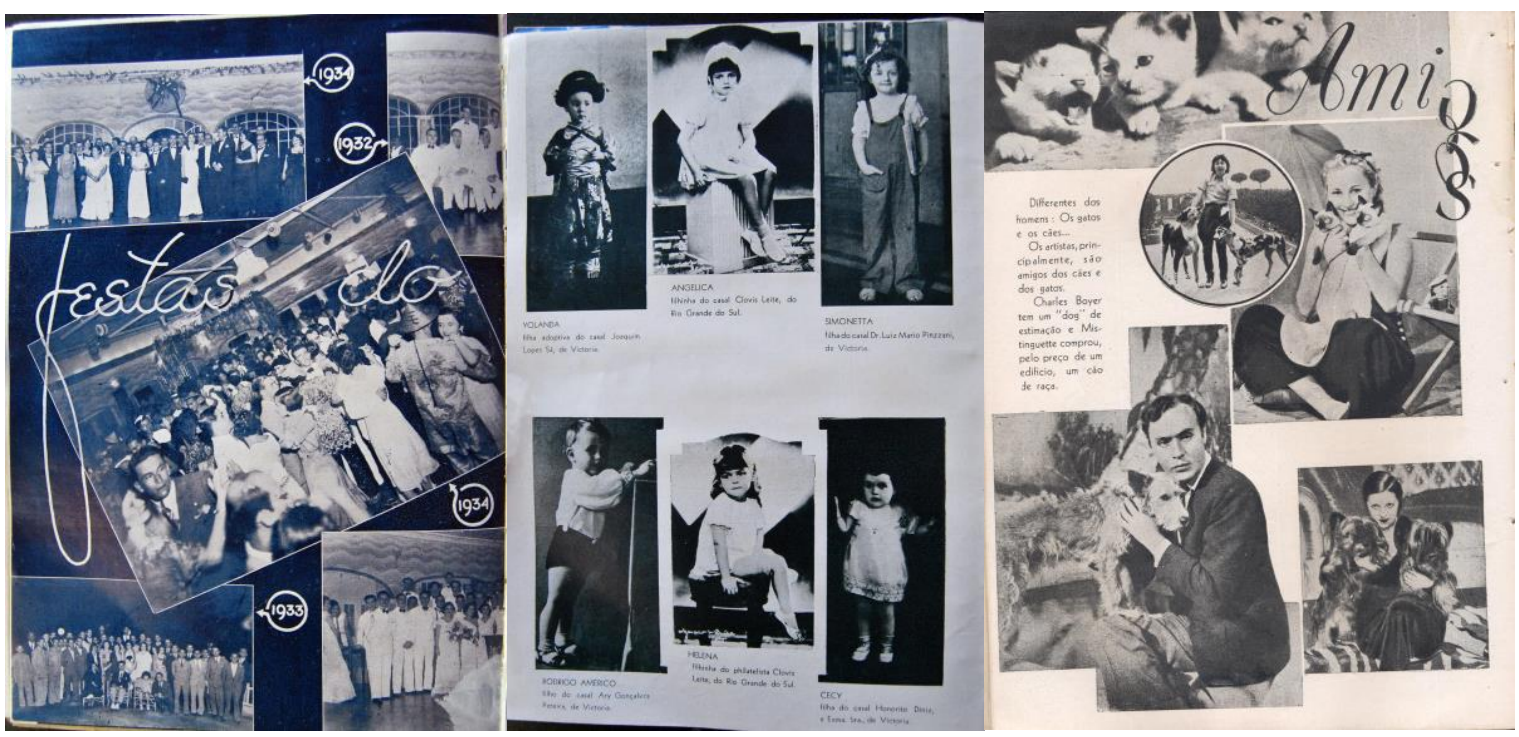

Fonte: Revista Chanaan Ed. 17, página 22, ano 1937; Revista Chanaan Ed. 16, página 30, ano 1937; Revista Chanaan Ed. 20, página 40, ano 1937. 


\section{Artigo Completo}

Imagem 7: Infográfico com os resultados da análise da categoria Composição de Página na revista Chanaan.

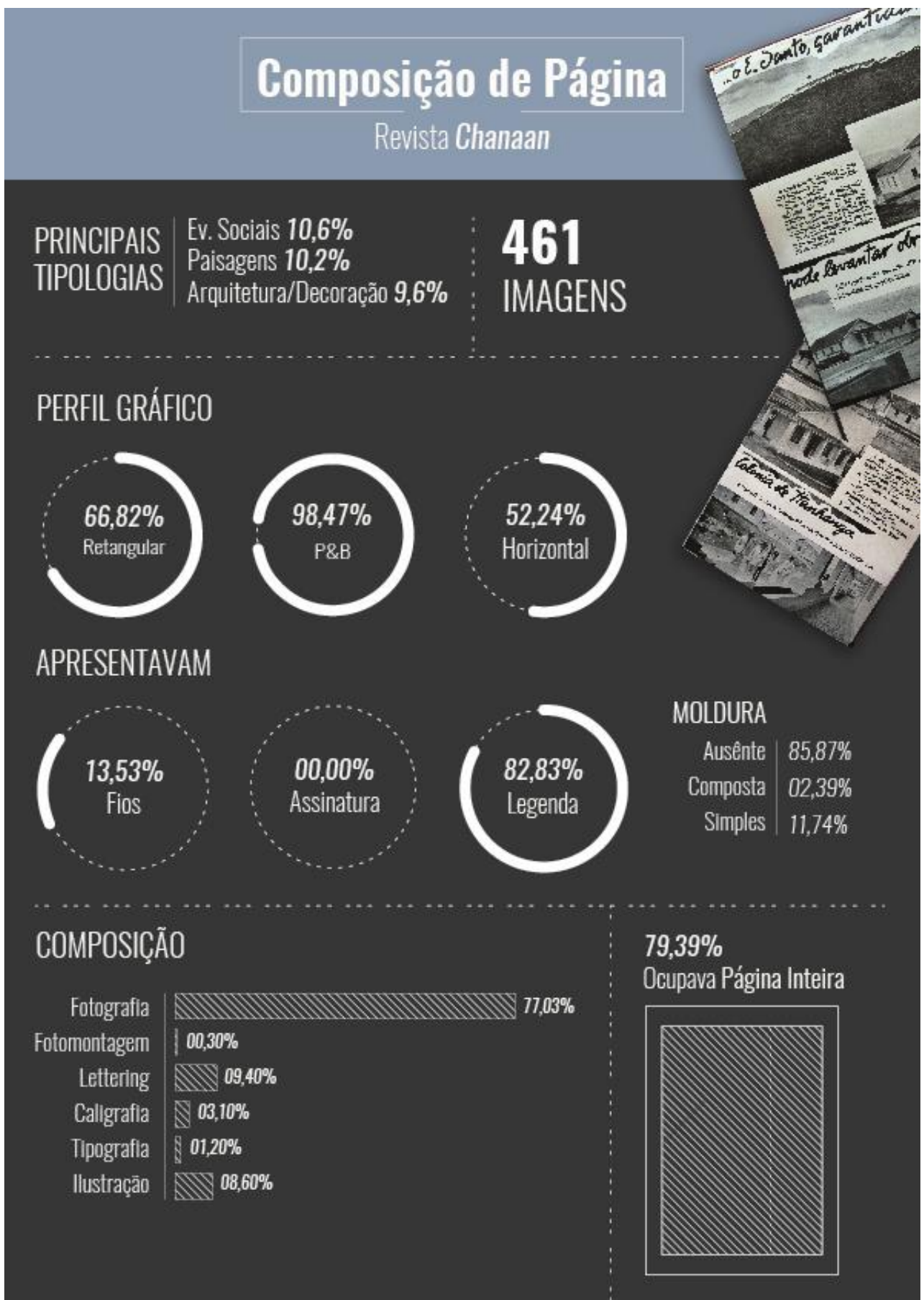

Fonte: Imagem produzida pelo autor.

\section{Ilustração}

Na categoria "ilustração" pôde-se perceber uma certa heterogeneidade devido a presença escassa de outros tratamentos gráficos em sua composição, como fotografia com 7,14\%, lettering com 5,80\%, caligrafia com 4,46\% e tipografia com 1,34\%. 66,67\% das ilustrações eram apresentadas de forma irregular, muitas vezes para se acomodar a diagramação da página, do texto e títulos. $48,48 \%$ ocupavam o topo da página, muitas vezes porque as ilustrações 
acompanhavam aberturas de seções e títulos principais. 92,78\% das ilustrações eram compostas em preto e branco e nenhuma apresentou qualquer tipo de fio. Apenas 9,64\% apresentaram assinatura e $15,74 \%$ legendas. O enquadramento ficou balanceado entre $52,75 \%$ de disjuntivo e $47,25 \%$ de conjuntivo, no qual pode-se encontrar respectivamente tanto desenhos soltos como atribuídos a fundos. $73,08 \%$ das ilustrações eram naturalistas, trazendo elementos e composições de nossa realidade. $60,44 \%$ apresentaram gama estendida, sendo composições mais complexas e com maior nível de detalhamento.

Das poucas ilustrações assinadas foi possível reconhecer os seguintes ilustradores: Ferreira, Semug, Mendez, Oséaz Leão, Belmonte, Wundher W., Augusto Salles, Hernest Panish, Renato Silva, Jeronymo Ribeiro, Cavalleira e Marge. É preciso esclarecer que devido ao caráter caligráfico e pessoal das assinaturas, alguns nomes citados podem conter algum erro de grafia pela dificuldade de identificação correta das letras.

Os ilustradores Leobaldo Ferreira, Ozeas Leão, Celita Silva e Eugenio Pelerano foram citados em uma pequena nota da revista e identificados como ilustradores capixabas responsáveis por publicações na mesma (Chanaan, ed. 10 p. 02). Cabe ressaltar que a partir do início do segundo ano do periódico o ilustrador Ozeas Leão foi citado no expediente da revista como ilustrador oficial da edição.

Imagem 8: Ilustrações da revista Chanaan.

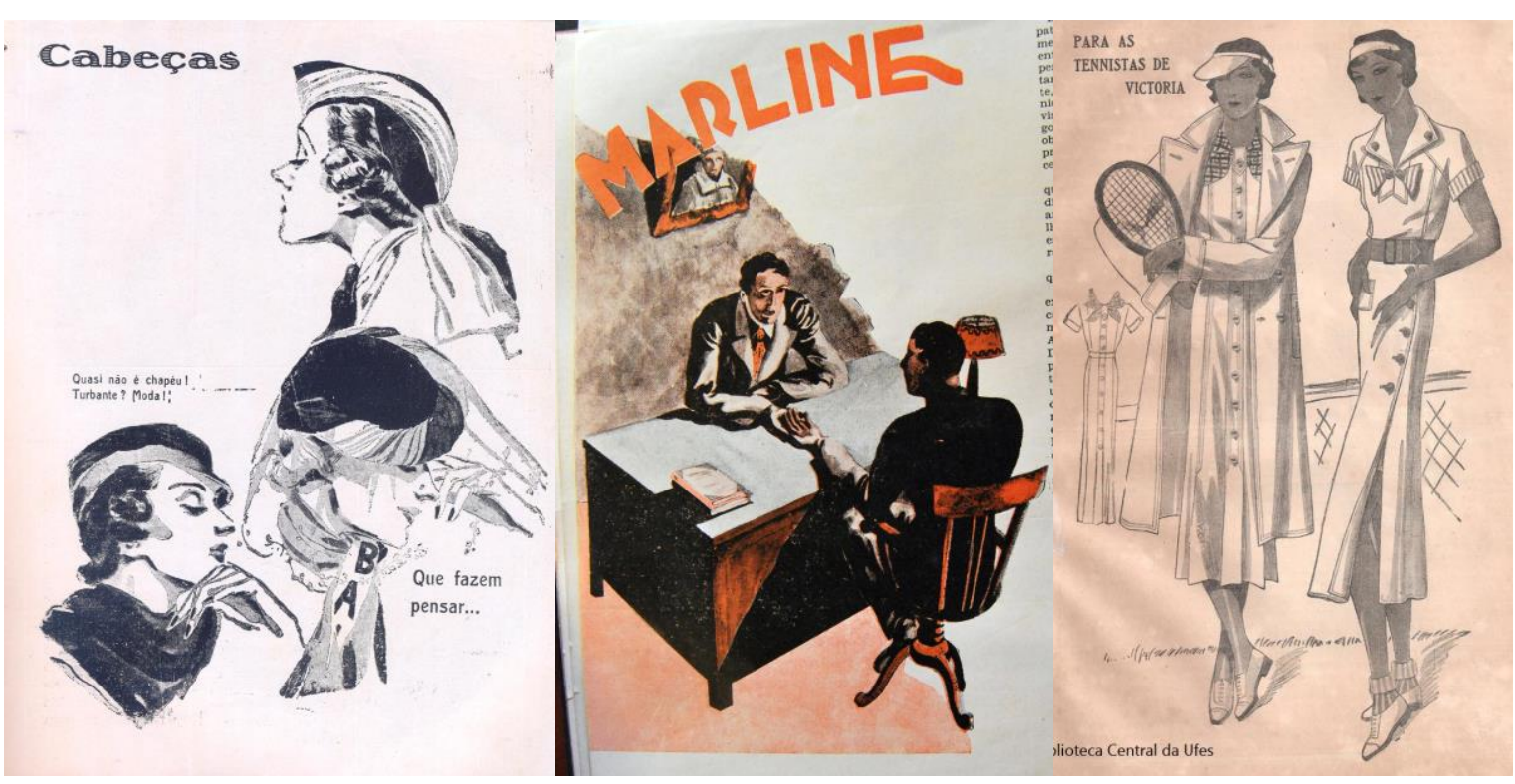

Fonte: Revista Chanaan Ed. 22 e 23, página 41, ano 1938; Revista Chanaan Ed. 14, página 14, ano 1937; Revista Chanaan Ed. 02, página 63, ano 1936. 


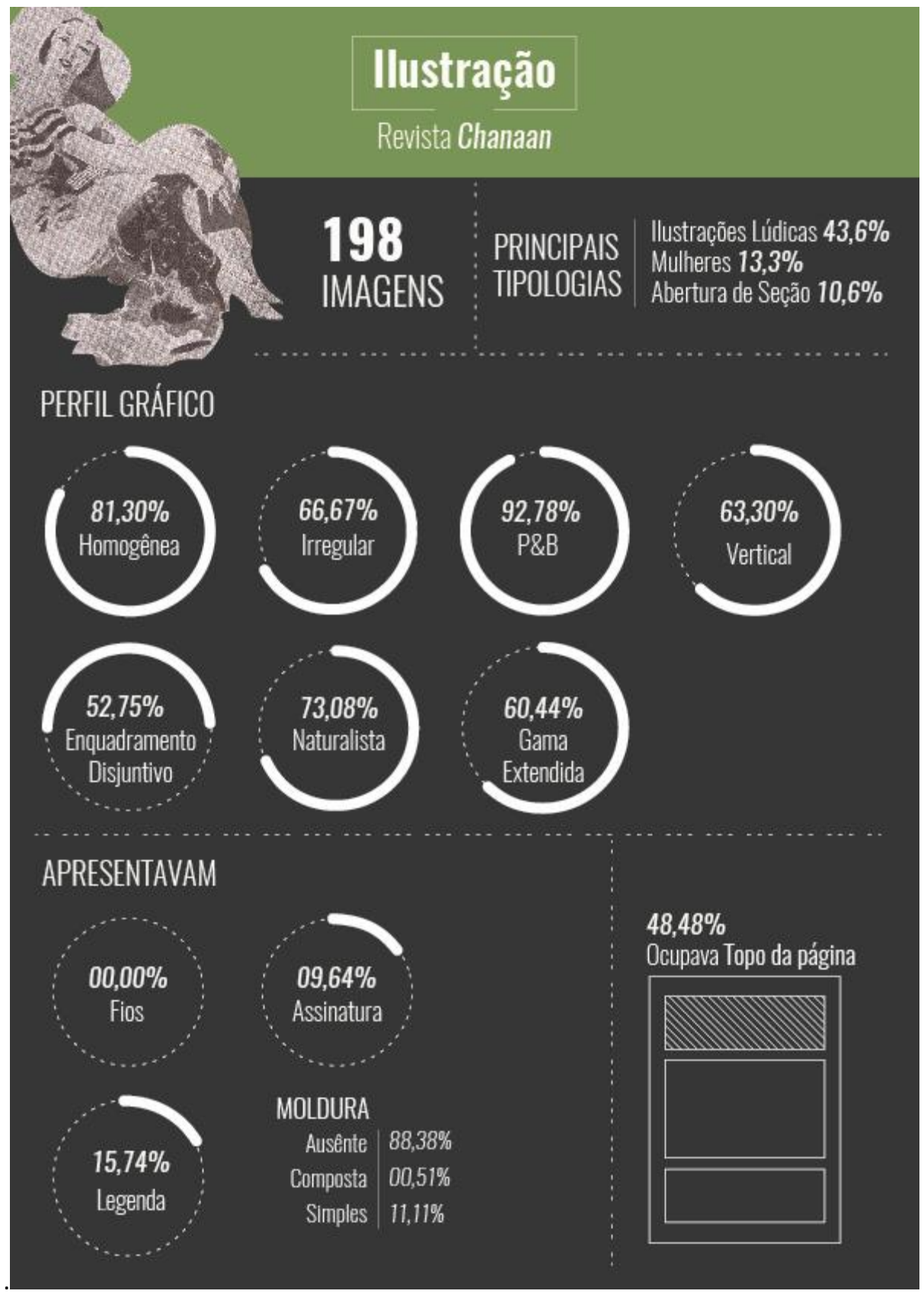

Fonte: Imagem produzida pelo autor.

\section{Conclusão}

A revista Chanaan se mostrou um periódico de caráter audacioso, que dentro dos limites técnicos da época buscava opções para trazer uma diagramação mais arrojada em algumas de suas páginas. O nível de experimentações gráficas relacionadas às imagens se mostrou considerável analisando as estatísticas supracitadas, já que usavam diversos artifícios gráficos para inovar, como: formatos diferenciados, orientações não convencionais como a transversal, mistura de tratamentos gráficos em uma só imagem, arranjos arrojados em suas composições de página e fotomontagens.

As ilustrações tiveram uma participação menor, porém não menos importante para a 
construção da identidade da revista, posto que ao observar seu comportamento e principais tipologias conclui-se que foram muito utilizadas para ilustrar e acompanhar textos e dar personalidade aos diversos títulos de seção. Deve-se a isso um caráter de apoio, com protagonismo menor do que a fotografia, que obtinha maior destaque nas páginas e que muitas vezes foi aclamada como obra artística dos fotógrafos que atuaram na revista. Poucas assinaturas foram encontradas nas ilustrações, fato que pode indicar que algumas delas eram clichês prontos e adquiridos para compor a diagramação, diferentemente da fotografia, que apresentava mais composições exclusivas para a revista.

A fotografia foi notoriamente o tipo de imagem mais utilizado na revista, em consequência de que, além de sua própria categoria, foi predominante nas fotomontagens e composições de página. O elevado uso de imagens tornou a Chanaan uma revista que deu ênfase ao conteúdo visual, já que se auto intitulava como "mensario illustrado", e empenhava-se em divulgar para a sociedade local e de outros estados a prosperidade e progresso da capital Vitória e de seu Estado.

Também foi de grande destaque a descoberta dos fotógrafos que atuaram ativamente na sociedade da época e foram responsáveis por preservar e conservar memórias. O estudo dos fotógrafos reforça que a revista Chanaan foi um periódico elitista e disseminava a ideia de um Estado idealizado.

Essas conclusões só foram possíveis devido à adaptação de classificações já existentes que sustentaram a metodologia e trouxeram um novo viés de interpretação gráfica e técnica da construção e uso destas imagens na revista Chanaan. Assim, foi possível validar conclusões através da análise do acervo como um todo, evitando resultados tendenciosos ou parciais que podem ocorrer ao se avaliar somente um recorte.

\section{Referências}

AZERÊDO, J. S.; TOSO, A. PEDRUZZI, L. Revista Chanaan e a memória gráfica capixaba. Congresso Nacional de Iniciação Científica em design da informação, Brasília, 2015.

AZERÊDO, J. S.; FONSECA, L. P... Análise dos anúncios da revista Chanaan. 12을 Congresso Brasileiro de Pesquisa e Desenvolvimento em Design,. São Paulo: Blucher Design Proceedings, v.9, n. 2., p. 382-394, 2016.

FONSECA, L. P., GOMES, D. D.; CAMPOS, A. P.. Conjunto Metodológico para Pesquisa em História do Design a partir de Materiais Impressos. Revista Brasileira de Design da Informação, São Paulo: InfoDesign, v. 13, n. 2., p. 143-161, 2016.

LIMA, R. O. C.. Análise da infografia jornalística. 143 f. Dissertação (Mestrado em Design) ESDI/UERJ, Rio de Janeiro, 2009.

MOREIRA, L. M.; FONSECA, L. P. Proposta de ficha de coleta de dados para análise de acervos de imagens. 8o Congresso Internacional de Design da Informação, Natal, 2017.

PASTE, R.. Vídeo/Rosana Paste. Vitória: UFES, Núcleo de Educação Aberta e a Distância, 2011.

PORTA, F.. Dicionário de artes gráficas. Rio de Janeiro: Globo, 1958

RODRIGUEZ, J. L, [2010-?]. Planos Fotográficos In: Dzoom, Acesso em: 4 de Março de 2017. (<http://www.dzoom.org.es/el-retrato-fotografico-tipos-de-plano/>). 